\title{
IN HOSPITAL CARDIAC ARREST MANAGED BY IMMEDIATE CORONARY ANGIOGRAPHY WITH OUTCOME OF SURVIVAL WITHOUT NEUROLOGICAL SEQUELAE : A CASE REPORT
}

Elif KILIC CAKMAK, Filiz UZUMCUGIL

Hacettepe University Faculty of Medicine, Department of Anesthesiology and

Reanimation, Ankara TURKEY

\section{Introduction:}

In order to improve patient outcomes, it is important to recognize cardiac arrest immediately for starting cardiopulmonary resuscitation by chest compression, ventilation and early defibrillation if needed ${ }^{1}$.

\section{Case report:}

A 68-year old man suddenly collapsed in the hallway at the hospital. A "code blue" was called. In 3 minutes, resuscitation team reached the scene while cardiopulmonary resuscitation(CPR) was being performed. The team confirmed cardio-respiratory arrest and took over CPR. The initial rhythm was ventricular fibrillation(VF); initial shock was given $(150 \mathrm{~J})$. In the second rhythm analysis, the rhythm was fine VF, CPR was continued without defibrillation and $1 \mathrm{mg}$ adrenaline was administered. After the third and fourth rhythm analysis, rhythm was VF; second and third shocks (360 J) were given in each cycle. After the third shock, return of spontaneous circulation(ROSC) was achieved.

During transportation of the patient to the emergency room (ER), VF recurred; the shock (360 J) was given immediately and the team started chest compression on the hospital stretcher.
In the ER, CPR continued for 8 cycles with the rhythm of VF on monitor. After ROSC in 35 minutes, the patient was transported to the catheterization lab for percutaneous coronary intervention(PCI). Following $\mathrm{PCl}$ (table 1) within 45 minutes, the patient did not require any vasopressors or inotrope agents. The trachea was extubated following the first 24 hours. The patient was discharged from the hospital after 6 days without any neurological sequelae.

3 weeks later, drug-eluting stent implanted to the occluded branch of right coronary artery in elective conditions.

\section{Table 1.}

The patient's percutaneous coronary intervention

\begin{tabular}{l} 
- occluded native left descending artery \\
\hline - intact left internal mammary artery-left descending \\
artery graft \\
\hline - drug-eluting stent implantation to the branch of \\
circumflex artery \\
\hline - occluded branch of right coronary artery \\
\hline
\end{tabular}

\section{Conclusion:}

Besides early recognition of cardiac arrest and early defibrillation, early $\mathrm{PCI}$ in recurring VF is to be highlighted to obtain ROSC without neurological sequelae. ${ }^{2}$ 